\title{
An Analysis on the Feasibility of Industrialization of Textile Intangible Cultural Heritage
}

\author{
Zhang Yuxin ${ }^{1, a}$, Ma Yanhua ${ }^{2, b}$, Ma Xiaohong ${ }^{3, c}$, Liu Yunyang ${ }^{4, d}$ \\ ${ }^{1}$ International economic and trade, Tianjin Polytechnic University, \\ Zhang Yuxin,900223, China \\ ${ }^{2}$ Economics, Tianjin Polytechni University, \\ Ma Yanhua ,700115, China \\ ${ }^{3}$ International economic and trade, Tianjin Polytechni University, \\ Ma Xiaohong, 710903, China \\ ${ }^{4}$ International economic and trade, Tianjin Polytechni University, \\ Liu Yunyang,900805, China \\ aemail: 695151895@qq.com, bemail:479234617@qq.com, \\ cemail:153665789@qq.com, demail:1219531@qq.com
}

Keywords: Textile Intangible Cultural Heritage; Industrialization; Analysis on Feasibility

\begin{abstract}
Textile intangible cultural heritage is the epitome of ancient Chinese culture, which is worthy of research. This paper gives an analysis on the feasibility of industrialization of textile intangible cultural heritage through several aspects and brings forward views on the protection and industrialization of textile intangible cultural heritage.
\end{abstract}

\section{Overview of textile intangible cultural heritage}

Textile intangible cultural heritage with its carrier, textile products, highlights the exquisiteness of traditional craftsmanship. It is the miniature of Chinese traditional national culture and is an essential part in Chinese and international intangible cultural heritage. However, along with the industrial economic development and lashes of the powerful foreign culture, the traditional production ways under manual economic mode have been affected by varying degrees, which makes the states quo of 65 identified textile intangible cultural heritage items worrisome.

\section{Overview of the analysis on the feasibility of industrialization}

\subsection{The impact of industrialization on textile intangible cultural heritage}

The industrialization of textile intangible heritage is the urge of technological innovation and market demands and the tendency of textile development in the future. Also, industrialization solves the heritor issue which further protects its development and inheritance. Thus, its industrialization and protection are complementary to each other and they are coordinated. On the one hand, the exploitation and utilization of textile intangible cultural heritage are based on its protection since it is nonrenewable. Blind exploitation with certain purpose might lead to the loss of intangible cultural heritage which is impossible to reappear. The lesson in this respect has been the deadliest. On the other hand, protecting and saving intangible cultural heritage is the premise of exploring it. The endangered intangible cultural heritage is the precondition of exploring and utilizing of its value, without which exploration and utilization would be a dead letter. Of course, people should be alert to social and foreign capitals, for too much attention on investment returns and the pursuit of profit maximization will lead intangible cultural heritage protection to wrong ways. The essence of intangible cultural heritage will be alienated and dismembered if all intangible cultural heritage items are brought into markets instinctively. And this goes counter to the original purpose of 
protection. Thus, it is necessary to give a study on the feasibility of textile intangible cultural heritage.

\subsection{An analysis on the feasibility of industrialization of textile intangible cultural heritage}

The industrialization process of textile intangible cultural heritage is not a process of simply chasing profit maximization, but a process of economic and cultural integration, acceleration and amplification. That is, culture creates economy, economy thrifts culture (fig 1). As for the industrialization of textile intangible cultural heritage, the way of industrialization is not unique. We need to take its type, endangered status, national integration, market value, operating environment, alternative markets and other factors into consideration and make out an industrialization path which suits its properties.

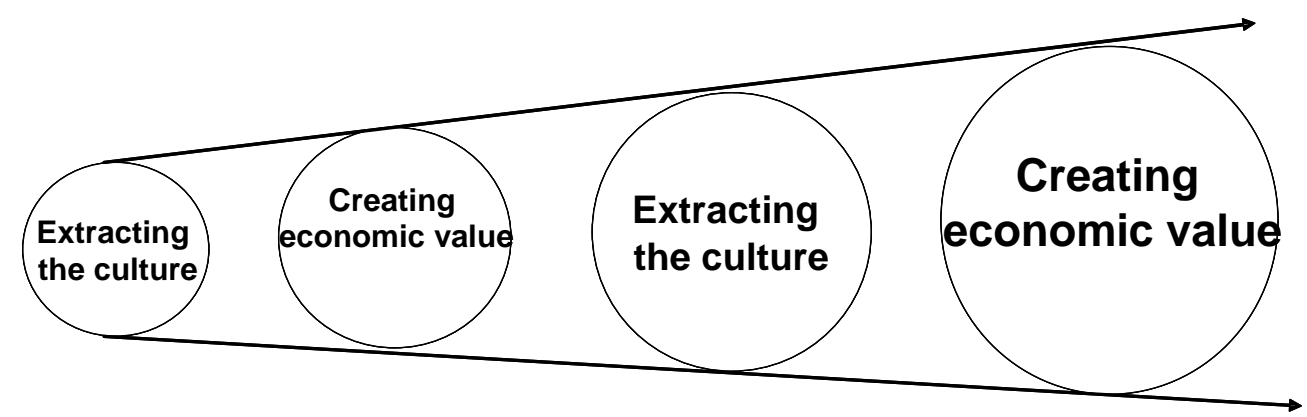

Fig 1 figure of economic and cultural amplification effect of textile intangible cultural heritage

The industrialization of textile intangible cultural heritage is determined by two factors: first, whether the textile intangible cultural heritage can be industrialized and this is the sufficient condition of industrialization of textile intangible cultural heritage; second, whether the textile intangible cultural heritage is worth industrialization and this is the prerequisite of industrialization of textile intangible cultural heritage. Only when the two conditions are met, the issue of industrialization can be discussed.

\subsubsection{Is industrialization of textile intangible cultural heritage allowed?}

\subsubsection{The bottom line of industrialization-----to meet the principle of protecting intangible cultural heritage}

The industrialization of textile intangible cultural heritage is to protect and inherit the intangible cultural heritage better. Thus, in dealing with the issue, the principle of not destroying but protecting the intangible cultural heritage must be fulfilled: (1) the truth, unity and inheritance of the culture. (2) cultural identity: reunification of the country, national unity; social harmony, sustainable development. This is the bottom-line of discussing industrialization and it must be fulfilled to explore ways of industrialization.

2.2.1.2 Condition of industrialization-the character of textile intangible cultural heritage suits for industrialization itself

Not all kinds of textile intangible cultural heritage are suitable to industrialization. This is determined by its conditions such as the type of the heritage, endangered status, ethnic fusion and so on. Some textile intangible cultural heritage, as the fish skin production techniques of Hoche nationality, the bark cloth production techniques of $\mathrm{Li}$ nationality are lack of conditions of industrialization and are not suitable to industrialization because of regional limitation and national exclusiveness, etc.

\subsubsection{Is textile intangible cultural heritage worth industrialization?}

The cultural and social values of textile intangible cultural heritage are beyond doubt, whereas the economic value it possesses or whether the economic value will be greater after industrialized 
exploration is unknown.

Not all of the intangible cultural heritage items are suitable to industrial management. The industrialization of intangible cultural heritage is subject to many factors. Whether the textile intangible cultural heritage is worth industrialization must be decided after fully considering the market value itself, the operating environment, alternative markets and so on. As for intangible cultural heritage items which have unique cultural value, good prospects for market development, a certain social basis and broader community participation, people can introduce in market mechanism and enhance the capacity and effect of industrial development, thereby expanding the cultural heritage visibility to further cultural identity in order to achieve the purpose of inheriting traditional Chinese culture. As for those with outstanding historic and economic values, but are dislocated from modern production and modern life, the government's guiding role is highlighted since they are severely endangered and productive protection of them can not produce a certain scale and effect. In this way, effective protection can be made by documenting heritage materials, creating files, identifying heritor, providing a teaching place, funding to carry out teaching activities and organizing promotion and exchange activities, etc.

\section{Discussion of modes of protecting and exploiting textile intangible cultural heritage}

\subsection{The overall principle of textile intangible cultural heritage protection}

Referring to the comprehensive protection of Chinese intangible cultural heritage, the General Office of the State Council of the People's Republic of China released The View of the State Council on Strengthening the Protection of Intangible Cultural Heritage and put forward the principle as "we protect them in most cases and save them at very crucial moments, we utilize them in a moderate manner, in order to inherit and develop them" in 2005. Later, three protection ways as rescuing protection, overall protection and productive protection are developed on the basis of it. And it is a macroscopic plan of the overall protection of intangible cultural heritage. Considering the characters of textile intangible cultural heritage, the writer holds that the protection and exploitation of them can be made under the guidance of it.

\subsection{The development mode of textile intangible cultural heritage}

The 65 Chinese textile intangible cultural heritage items at present are the culture created in human society and are parts of human spiritual civilization in nature. The flourish, decline and disappearance of old culture and the sprout and the rise of the new culture are invariable rules of development. The study on inheritance, protection and development of intangible cultural heritage is a kind of admiration of splendid civilization of human history and a kind of return in essence. Just as the rising granny chic current all over the world, its essence is to promote cultural diversity and plural aesthetics and enrich people's lives.

So the protection and exploitation of them should be done with the guidance of creating multi-culture on the basis of the characters of textile intangible cultural heritage. Hence, the stratified exploitation mode is brought forward in target to all textile intangible cultural heritages.

The first type is the heritage that can be fully exploited as represented by four famous embroideries, four famous brocades, Miao embroidery and Han embroidery. This type of intangible cultural heritage is characterized by its high reproducibility, its widely used products and its values in history, art, aesthetics, life and many other aspects. Thus, they can be commercialized again when appropriate development measures are taken.

The second type is the heritage that we mainly protect it but exploit it moderately. This kind of heritage is represented by some national minority textile intangible cultural heritage like Wu Ni Jing cotton manufacturing craft, wool manufacturing technology and Feng Xiang printing and dyeing art in south of Gui Zhou Province. It has certain applications and reproducibility, but the main job of people is to protect its authenticity, since over-exploitation of it may move out of its genetic characteristics. Thus, strategies as establishing museums and experiencing halls, heritor training and some related cultural and economic development strategies can be adopted.

The third type is heritage that is difficult to exploit as represented by fish skin making skills of 
Hoche nationality and the bark cloth making skill of Li nationality. Its distinctive regional culture and national character make it limited in skill and narrow in material selection, content, application and reproducibility. As a culture with unique characteristics, this kind of textile intangible cultural heritage has more historic, national and regional characters, so the market demand is limited and the exploitation degree is relatively low. Thus, it is of great necessity to do comprehensive searching, recording, filing and keeping.

\section{References}

[1]Zhang Xiaoqing.Development of low-carbon economy on China's export trade impact analysis[J].Inner Mongolia University.2010.6

[2]Yuan Li、Gu Jun.Intangible Cultural Heritage[J].Higher Education Press.2009.11

[3]Mou Yanlin、Tan Hong、 Liu Zhuang.Introduction to Cultural Heritage[J].Beijing Normal University Press.2010.1

[4]China Textile Industry.China Textile Industry Development Report 2011-2012[J].China Textile Press.2012.5

[5]LI Qi. Non-material cultural heritage protection and industrial management to explore[A]. Industrial and Commercial University Of Chongqing. 2008

[6] Assoc ham Financial Pulse Study. Analysis of Second Quarter Results of Textile Sector [EB/OL]. http://www.assocham.org/arb/afp.php ,Nov 2008. 